\title{
Diferentes concentrações de ácido naftalenoacético no estabelecimento in vitro de mandioca
}

\author{
Eyllen Serrão Martins ${ }^{a *}$, Tanara Pletsch Dalla Costa ${ }^{a} \bullet$, Eliandra de Freitas $\operatorname{Sia}^{\mathrm{a}} \oplus^{\oplus}$, \\ Rogério Rangel Rodrigues ${ }^{\mathrm{b}}$ (]) \\ a Universidade Federal do Oeste do Pará, Brasil \\ b Instituto Federal de Educação, Ciência e Tecnologia do Pará, Brasil \\ *Autor correspondente (eyllen-itb@hotmail.com)
}

\section{N F O}

\section{Keywords}

micropropagation

Manihot esculenta

phytoregulators
Palavras-chaves micropropagação Manihot esculenta fitorreguladores

\begin{abstract}
A B S T R A C T
Different concentrations of naphthaleneacetic acid in the in vitro establishment of cassava.

Cassava culture has high socioeconomic relevance for Brazil. However, in the western region of Pará, the spread of pests and diseases, among other factors, has limited root production. In this way, micropropagation becomes an alternative to traditional cultivation methods for obtaining material with phytosanitary quality. The objective of this study was to evaluate the effect of different concentrations of naphthalene acetic acid (ANA) in the in vitro establishment of stem apexes of the cassava variety Água Morna. The stem apexes were introduced into MS medium, supplemented with $0.04 \mathrm{mg} \mathrm{L}^{-1}$ of 6benzylaminopurine, $0.05 \mathrm{mg} \mathrm{L}^{-1}$ of gibberellic acid and different concentrations of ANA $\left(0.00 \mathrm{mg} \mathrm{L}^{-1}\right.$; $0.01 \mathrm{mg} \mathrm{L}^{-1} ; 0.02 \mathrm{mg} \mathrm{L}^{-1}$ and $0.03 \mathrm{mg} \mathrm{L}^{-1}$ ). The experimental design was completely randomized, with five treatments, containing five replicates of five tubes each. Over 30 days, the height of the seedlings, number of green and dead leaves, number of roots and the length of the largest root were evaluated. The seedlings showed average values of $1.51 \mathrm{~cm}$ in height, 1.51 green leaves, 1.67 roots and $1.31 \mathrm{~cm}$ in length from the largest root. The control treatment provided the least number of dead leaves, with an average of 0.52 leaves. There were no significant differences between ANA concentrations for the other variables analyzed, except for the number of dead leaves. Therefore, the in vitro establishment of the Água Morna cassava variety was efficient in all treatments, and the culture medium without growth regulators could be used.
\end{abstract}

\section{R E S U M O}

A cultura da mandioca apresenta alta relevância socioeconômica para o Brasil. Entretanto, na região Oeste do Pará, a disseminação de pragas e doenças, entre outros fatores, tem limitado a produção de raízes. Desta forma, a micropropagação torna-se uma alternativa aos métodos tradicionais de cultivo para a obtenção de material com qualidade fitossanitária. Objetivou-se neste estudo avaliar o efeito de diferentes concentrações de ácido naftalenoacético (ANA) no estabelecimento in vitro de ápices caulinares de mandioca da variedade Água Morna. Os ápices caulinares foram introduzidos em meio MS, suplementado com $0,04 \mathrm{mg} \mathrm{L}^{-1}$ de 6-benzilaminopurina, $0,05 \mathrm{mg} \mathrm{L}^{-1}$ de ácido giberélico e diferentes concentrações de ANA $\left(0,00 \mathrm{mg} \mathrm{L}^{-1} ; 0,01 \mathrm{mg} \mathrm{L}^{-1} ; 0,02 \mathrm{mg} \mathrm{L}^{-1}\right.$ e $\left.0,03 \mathrm{mg} \mathrm{L}^{-1}\right)$. O delineamento experimental foi inteiramente casualizado, com cinco tratamentos, contendo cinco repetições de cinco tubos cada. Ao longo de 30 dias, avaliou-se a altura das plântulas, número de folhas verdes e mortas, números de raízes e o comprimento da maior raiz. As plântulas apresentaram valores médios de 1,51 cm de altura, 1,51 folhas verdes, 1,67 raízes e $1,31 \mathrm{~cm}$ de comprimento da maior raiz. O tratamento controle proporcionou o menor número de folhas mortas, cuja média foi de 0,52 folhas. Não houve diferenças significativas entre as concentrações de ANA para as demais variáveis analisadas, exceto para número de folhas mortas. Portanto, o estabelecimento in vitro da mandioca variedade Água Morna foi eficiente em todos os tratamentos, podendo o meio de cultura isento de reguladores de crescimento ser empregado. 


\section{INTRODUÇÃO}

A mandioca (Manihot esculenta Crantz) é originária da América do Sul e todas as espécies de Manihot são nativas do continente americano (Fialho et al., 2011). É a única espécie do gênero amplamente cultivada nas regiões tropicais e subtropicais do mundo e por sua elevada quantidade de amido, torna-se estratégica em nível mundial (Soares et al., 2016), sendo atualmente uma fonte de carboidratos consumida por mais de 800 milhões de pessoas nos trópicos (Saravanan et al., 2016).

Cultivada em todas regiões do Brasil, a maior produção de mandioca se concentra nas regiões Norte e Nordeste, sendo o estado do Pará um dos principais produtores e consumidores (Guimarães et al., 2017). De acordo com os dados do IBGE (2018), o município de Santarém/PA ocupa o terceiro lugar na produção estadual de raízes.

Dentre as variedades de mandioca comercializadas no município de Santarém/PA, a mandioca denominada de Água Morna destaca-se como uma das variedades de mesa apreciada na culinária regional.

Entretanto, há fatores limitantes da produção de mandioca na região do Oeste do Pará, com destaque à podridão radicular causada pelo fungo Fusariun solani que desde 2002 vem causando severas perdas e o manejo rudimentar dos pequenos agricultores, sem a realização de seleção das manivas - sementes (Alves et al., 2008; Boas et al., 2016).

A propagação vegetativa da mandioca realizada pelo corte de manivas facilita a livre troca de hastes entre os agricultores para o plantio (Faye et al., 2015), porém, permite a disseminação de doenças, transmissão de pragas e patógenos, reduzindo a disponibilidade de material propagativo de qualidade (Kidulile et al., 2018). Desta forma, a biotecnologia, por meio da cultura de tecidos vegetais, constitui-se de método alternativo para amenizar esses problemas fitossanitários, mediante a técnica de micropropagação (Hora et al., 2015). A técnica consiste no cultivo in vitro de plantas, com meio nutritivo adequado, em que a adição de reguladores de crescimento estabelece um eficiente controle no crescimento e na diferenciação das culturas in vitro (Skoog et al., 1957).

Dada a importância da variedade e o crescente uso industrial do amido da mandioca na região Oeste do Pará, faz-se necessária a realização de pesquisas que visem a identificação de material de propagação com qualidade genética e fitossanitária. Assim, objetivou-se avaliar o estabelecimento in vitro de ápices caulinares de mandioca da variedade Água Morna, testando diferentes concentrações do regulador de crescimento vegetal ácido naftalenoacético (ANA).

\section{MATERIAL E MÉTODOS}

O trabalho foi conduzido no Laboratório de Micropropagação de Plantas in vitro da Universidade Federal do Oeste do Pará (UFOPA) em parceria com o Instituto Federal do Pará (IFPA), no primeiro semestre de 2018. O material vegetal foi constituído de manivas com idade de 10 meses, as quais foram fornecidas por produtor rural do município de Belterra (PA).

As manivas foram plantadas em bandejas plásticas contendo fibra de coco (Sococo) e substrato comercial (PlantMax®), na proporção de 1:1, mantidas em viveiro de mudas sob telado a $50 \%$ de sombreamento. A irrigação automatizada foi realizada por microaspersão, duas vezes por dia durante cinco minutos. Após 21 dias de plantio, foram coletados os ápices caulinares usados como explantes para experimento.

Os explantes foram desinfestados em câmara de fluxo laminar, imersos em álcool a $50 \%(\mathrm{v} / \mathrm{v})$, por um minuto, e em água destilada esterilizada, por 30 segundos. Posteriormente, foram imersos em hipoclorito de sódio comercial (Qboaß) a $0,25 \%$ $(\mathrm{v} / \mathrm{v})$, por três minutos, seguido de tríplice lavagem em água destilada esterilizada. Sob o campo visual do microscópio estereoscópio, os ápices caulinares foram reduzidos em aproximadamente quatro primórdios foliares, eliminando-se gradativamente folhas e estípulas (Souza e Junghans, 2013).

$\mathrm{O}$ delineamento foi inteiramente casualizado (DIC), com cinco repetições de cinco tubos, sendo cada tubo constituído de um ápice caulinar, totalizando 25 explantes. $\mathrm{O}$ experimento constituiu-se de cinco tratamentos T1 - meio MS na ausência de reguladores de crescimento (controle); T2 - 0,0 $\mathrm{mg} \mathrm{L}^{-1}$ de ANA; T3 - 0,01 mg $\mathrm{L}^{-1}$ de ANA; T4 - 0,02 mg L ${ }^{-1}$ de ANA; T5 - 0,03 mg L ${ }^{-1}$ de ANA.

Os ápices caulinares foram inoculados em tubos de ensaio (30x150 mm) contendo meio MS (Murashige e Skoog, 1962 - Sigma-Aldrich) suplementado com $20 \mathrm{~g} \mathrm{~L}^{-1}$ de sacarose, $0,04 \mathrm{mg} \mathrm{L}^{-}$ ${ }^{1}$ de BAP (6-benzilaminopurina), $0,05 \mathrm{mg} \mathrm{L}^{-1} \mathrm{AG}_{3}$ (ácido giberélico) e diferentes concentrações de ANA (ácido naftalenoacético). $\mathrm{O}$ meio de cultura foi solidificado com $2 \mathrm{~g} \mathrm{~L}^{-1}$ de Phytagel ${ }^{\circledR}$, cujo $\mathrm{pH}$ foi ajustado para $5,7 \pm 0,1$, e autoclavado a $121{ }^{\circ} \mathrm{C}$ sob pressão de $1 \mathrm{~atm}$ durante 20 minutos.

Os tubos permaneceram em sala de crescimento iluminada com lâmpadas fluorescentes brancas frias, com densidade de fluxo de fótons de 30 $\mu$ mol. $\mathrm{m}^{2}$ s $^{-1}$, fotoperíodo de 16 horas e temperatura de $27{ }^{\circ} \mathrm{C} \pm 2{ }^{\circ} \mathrm{C}$. Após 30 dias de cultivo in vitro, foram avaliadas: altura das plântulas $(\mathrm{cm})$, número 
de folhas verdes, número de folhas mortas, números de raízes e comprimento da maior raiz $(\mathrm{cm})$. A altura das plântulas e o comprimento das raízes foram medidos com o auxílio de um paquímetro, da base da brotação até a inserção da folha mais nova e da base da brotação até o final da maior raiz, respectivamente.

Os dados foram submetidos a análise de variância (ANOVA) e as médias foram comparadas pelo Teste de Tukey a 5\% de probabilidade de erro, com o auxílio do software estatístico Sisvar® (Ferreira, 2014).

\section{RESULTADOS E DISCUSSÃO}

Ao longo dos 30 dias de cultivo in vitro, observou-se que os tratamentos T4 e T5 apresentaram surgimento mais rápido das folhas, entre o quinto e oitavo dia de cultivo, o que não aconteceu com os demais tratamentos, nos quais as folhas surgiram somente a partir do décimo dia. Após 15 dias de cultivo, observou-se a formação das primeiras raízes em todos os tratamentos. Ao concluir 25 dias, todos os tratamentos apresentaram resposta ao desenvolvimento de raízes e folhas.

A adição de reguladores de crescimento ao meio de cultura pode promover, inibir ou, modificar o crescimento vegetal quando cultivados in vitro (Hartmann et al., 2002). Segundo Silva et al. (2015), a espécie e o tipo de explante respondem diferentemente à ação dos diversos tipos de reguladores de crescimento utilizados em culturas in vitro.

De acordo com a análise de variância (Tabela 1), não foram observadas diferenças significativas entre as concentrações de ANA no estabelecimento dos ápices caulinares de mandioca para os parâmetros altura das plântulas, número de folhas verdes, números de raízes e comprimento da maior raiz.

Tabela 1 - Análise de variância no estabelecimento in vitro da variedade de mandioca Água Morna sob diferentes concentrações de ácido naftalenoacético.

\begin{tabular}{ccccccc}
\hline \multirow{2}{*}{ Fonte de variação } & \multirow{2}{*}{ GL } & \multicolumn{7}{c}{ QM } \\
\cline { 3 - 7 } & & ALT & NFV & NFM & NR & CR \\
\hline Tratamentos & 4 & $0,05^{\text {ns }}$ & $0,92^{\text {ns }}$ & $0,03^{*}$ & $0,95^{\text {ns }}$ & $0,26^{\text {ns }}$ \\
Erro & 20 & 0,16 & 0,09 & 0,08 & 0,17 & 0,11 \\
Total & 24 & & & & & \\
\hline CV $(\%)$ & & 24,21 & 13,76 & 15,20 & 26,56 & 17,34 \\
Média & & 1,51 & 1,51 & 1,00 & 1,67 & 1,31 \\
\hline
\end{tabular}

*Efeito significativo ao nível de $5 \%$ pelo teste de Tukey.

${ }^{\text {n.s }}$ não significativo.

Houve efeito significativo apenas para número de folhas mortas (Tabela 1), sendo observado que o aumento da concentração do regulador de crescimento ANA foi diretamente proporcional ao maior número de folhas mortas. T1 apresentou o menor número de folhas mortas em relação aos demais tratamentos, com perda de 0,52 folhas. Por sua vez, o $\mathrm{T} 5$ alcançou a maior média de folhas mortas, com 1,44 folhas (Tabela 2).

Tabela 2 - Valores médios de altura das plântulas (ALT $-\mathrm{cm})$, número de folhas verdes (NFV), número de folhas mortas (NFM), número de raízes (NR) e comprimento da maior raiz (CR - $\mathrm{cm}$ ) em estabelecimento in vitro da variedade de mandioca Água sob diferentes concentrações de ácido naftalenoacético.

\begin{tabular}{cccccc}
\hline \multirow{2}{*}{ Tratamentos } & \multicolumn{5}{c}{ VARIÁVEIS } \\
\cline { 2 - 6 } & ALT $^{\text {ns }}$ & NFV $^{\text {ns }}$ & NFM $^{*}$ & NR $^{\text {ns }}$ & CR $^{\text {ns }}$ \\
\hline 1 & 1,16 & 1,84 & $0,52 \mathrm{a}$ & 1,82 & 1,59 \\
2 & 1,81 & 1,37 & $0,96 \mathrm{ab}$ & 1,60 & 1,09 \\
3 & 1,30 & 1,36 & $0,84 \mathrm{ab}$ & 1,41 & 1,10 \\
4 & 1,62 & 1,65 & $1,26 \mathrm{ab}$ & 1,85 & 1,59 \\
5 & 1,69 & 1,36 & $1,44 \mathrm{~b}$ & 1,66 & 1,22 \\
\hline
\end{tabular}

\footnotetext{
*As médias seguidas pela mesma letra da coluna não diferem de acordo com o teste de Tukey, ao nível de 5\% de probabilidade.

ns não significativo

Tratamentos: T1 - Controle; T2 - 0,00 mg L ${ }^{-1}$ de ANA; T3 - 0,01 mg L-1 de ANA; T4 - 0,02 mg L L $^{-1}$ de ANA; T5 - 0,03 mg L-1 de ANA.
} 
A acentuada perda de folhas e, consequentemente, o enfraquecimento das hastes das plântulas podem acarretar na perda do material vegetal. Segundo Vidal (2009), esse fato pode estar relacionado à exaustão de algum componente do meio de cultura.

A condição de crescimento do material vegetal na cultura de tecidos vegetais é geralmente feita em frascos ou tubos fechados, o que contribui para o acúmulo de compostos voláteis que são liberados nos recipientes e, em muitos casos, o acúmulo do composto de etileno pode ser prejudicial ao crescimento e desenvolvimento da cultura. Além disso, concentrações supra-ótimas de auxinas estimulam a produção de etileno e, consequentemente, a queda das folhas (Cid et al., 2014). Assim, pode-se supor que o maior número de folhas mortas esteja relacionado à liberação de etileno.

Em relação aos demais parâmetros analisados, foi observado que as diferentes concentrações de ANA não promoveram diferenças significativas nos resultados obtidos. De acordo com Kabir et al. (2015), no estabelecimento in vitro de mandioca o aumento do nível de reguladores de crescimento pode reforçar ou não a proliferação das gemas, uma vez que quase todas as espécies de plantas possuem teores razoáveis de hormônios endógenos, existindo apenas um nível ótimo de regulador de crescimento para a sua regeneração e multiplicação.

Assim, é possível que a variedade de mandioca Água Morna, utilizada neste experimento, tenha níveis endógenos de hormônios suficientes para seu desenvolvimento in vitro nos primeiros 30 dias de cultivo, uma vez que o tratamento controle não diferiu estatisticamente dos tratamentos com adição de ANA.

Neste sentindo, levando em consideração o alto custo da técnica de cultura de tecidos (Kidulile et al., 2018), o estabelecimento in vitro de plântulas de mandioca da variedade Água morna sem o uso de reguladores de crescimento possibilita a redução nos custos, principalmente no consumo dos reagentes adicionados ao meio de cultura.

\section{CONCLUSÕES}

O estabelecimento in vitro da variedade Água Morna foi eficiente em todos os tratamentos, independente do uso e das concentrações de ANA. Portanto, o meio de cultura isento de reguladores de crescimento pode ser empregado no estabelecimento in vitro da variedade de mandioca Água Morna.

\section{REFERÊNCIAS BIBLIOGRÁFICAS}

Alves RNB, Modesto Júnior MS, Andrade ACS. O trio da produtividade na cultura da mandioca estudo de caso de adoção de tecnologias na região no Baixo Tocantins, Estado do Pará. Congresso da associação brasileira das instituições de pesquisa tecnológica. Campina Grande, PB. 2008.

Boas SAV, Hohenfeld CS, Oliveira SAS, Santos VS, Oliveira EJ. Sources of resistance to cassava root rot caused by Fusarium spp.: A genotypic approach. Springer Netherlands. Euphytica, v.209, n.1, p.237-251, 2016.

Cid LPB, Teixeira JB. Explante, meio nutritivo, luz e temperatura. In: CID, LPB. Cultivo in vitro de plantas. 3. ed. Ampl. - Brasília, DF: Embrapa, p.17-51, 2014.

Faye A, Sagna M, Kane PD, Sane D. Effects of different hormones on organogenesis in vitro of some varieties of cassava (Manihot esculenta Crantz) grown in Senegal. African Jounal of Plant Science, v.9, p.305-312, 2015.

Ferreira CF. Molecular characterization of cassava (Manihot esculenta Cranz) with. Ferreira, Daniel Furtado. Sisvar: a computer statistical analysis system. Ciência e Agrotecnologia (UFLA), v.35, n.6, p.1039-1042, 2014.

Fialho JF, Vieira EA. Mandioca no Cerrado: Orientações técnicas. Planaltina, DF: Embrapa Cerrados. p.208, 2011.

Guimarães DG, Prates CJN, Cardoso AD. et al. Caracterização morfológica de genótipos de mandioca (Manihot esculenta Crantz). Scientia Plena, v.13, n.09, p.1-11, 2017.

Hartmann HT. et al. Plant propagation: principles and practices. New Jersey: Prentice-Hall, 7.ed. 880p. 2002.

Hora RAC, Souza AS, Silveira MS et al. Micropropagação de genótipos de mandioca via microestacas oriundas de diferentes posições da planta. In: Jornada Científica. EMBRAPA e fruticultura. 2015.

IBGE - Instituto Brasileiro de Geografia e Estatística / Sistema IBGE de Recuperação Automática - SIDRA. Área colhida, área plantada e produção, por ano da safra e produto das lavouras. 2018. Disponível em: <https://sidra.ibge.gov.br/tabela/1612\#resultado>. Acesso em 16 de março de 2018.

Kabir MH, Mamun ANK, Roy PK, Islam MR, Johan MT, Talukder SU. In vitro propagation of cassava (Manihot esculenta Crantz). Nuclear science and applications, v.24, n.1\&2, p.23-28, 2015.

Kidulile CE, Alakonya AE, Ndunguru JA, Ateka EM. Cost effective medium for in vitro propagation of Tanzanian cassava landraces. African Journal of Biotechnology, v.17, p.787-794, 2018.

Murashige T, Skoog FA. A revised medium for rapid growth and bioassays with tobacco tissue culture. Physiologia Plantarum, v.15, p.473-497, 1962.

Saravanan R, Ravi V, Stephen R, Thajudhin S, George J. Post-harvest physiological deterioration of cassava (Manihot esculenta) - A review. Indian Journal of Agricultural Sciences, p.1383-1390, 2016.

Silva S, Ferreira FF, Gato AMG. Efeitos de diferentes concentrações de 6-Benzilaminopurina no cultivo in vitro de 
Manihot esculenta Crantz. Scientia Amazonia, v.4, p.105111, 2015.

Skoog F, Miller CO. Chemical regulation of growth and organ formation in plant tissues cultured in vitro. Symposium for the Society Experimental Biology, v.11, p.118-131, 1957.

Soares IA, Téo MS, Debastiani C, Retuci VS, Baroni, S. Concentrado proteico obtido das folhas de mandioca ( $\mathrm{Ma}$ nihot esculenta Crantz) de três variedades de comerciais. Acta Ambiental Catarinense, v.13, p.1-7, 2016.

Souza A. da S. (Ed.); Junghans TG. Aspectos práticos da micropropagação de plantas. Cruz das Almas: Embrapa Mandioca e Fruticultura Tropical, p.407, 2013.

Vidal AM. Micropropagação e embriogênese somática em variedades cultivadas de mandioca. Ano de obtenção:2009. 59p. Dissertação (Mestrado em Ciências Agrárias) - Universidade Federal do Recôncavo da Bahia, Cruz das Almas. 